\title{
Moesin Up-regulation Is Associated with Enhanced Tumor Progression Imaged Non-invasively in an Orthotopic Mouse Model of Human Glioblastoma
}

\author{
QING WANG ${ }^{1}$, XIAOJIE LU $^{1}$, JING WANG $^{1}$, ZHIJIAN YANG $^{2,3}$, ROBERT M. HOFFMAN $^{3,4}$ and XUECHAO WU $^{1}$ \\ ${ }^{1}$ Department of Neurosurgery, Neuroscience Center, \\ Affiliated Wuxi Second Hospital of Nanjing Medical University, Wuxi, P.R. China; \\ ${ }^{2}$ Origin Biosciences Inc., Nanjing, P.R. China; \\ ${ }^{3}$ AntiCancer, Inc., San Diego, CA, U.S.A.; \\ ${ }^{4}$ Department of Surgery, University of California, San Diego, CA, U.S.A.
}

\begin{abstract}
Background/Aim: Glioblastoma is a recalcitrant and poorly understood disease. The aim of the present study was to investigate the effect of moesin up-regulation on tumor progression in an orthotopic nude-mouse model of human glioblastoma. Materials and Methods: U87-GFP glioblastoma cells, transfected with either U87-H4645 (moesin up-regulated) or U87-H149 (vector control) were orthotopically implanted into the brains of nude mice. Moesin expression in the tumors was analyzed with RT-PCR and western blotting. Real-time fluorescence imaging was used to longitudinally and noninvasively quantitate tumor growth. The expression of cancerrelated genes $\beta$-catenin, CD44, MMP-2, ICAM-1, and PCNA in the tumor was analyzed by RT-PCR, western blotting and immunohistochemistry in both sublines. Results: The expression levels of moesin mRNA and protein were significantly increased in the glioblastoma derived from transfected U87-H4645 cells compared to the vector control and untransfected cells. Tumor growth rate and final tumor weight were significantly increased in the animals with the glioblastoma derived from transfected U87-H4645 cells, compared to untransfected and vector control $(p<0.01)$. mRNA expression of $\beta$-catenin, CD44, ICAM-1, and $M M P-2$ in the glioblastoma derived from the transfected U87H4645 tumors was significantly increased compared with tumors derived from untransfected and vector-control U87 cells $(p<0.01)$. Furthermore, a similar increase in the expression of
\end{abstract}

This article is freely accessible online.

Correspondence to: Qing Wang, Department of Neurosurgery, Neuroscience Center, Affiliated Wuxi Second Hospital of Nanjing Medical University, Wuxi, Jiangsu Province, P.R. China. Tel: +86 51068562741, Fax: +86 51068562052, e-mail:wxwqnj@163.com

Key Words: Moesin, progression, glioblastoma. these proteins was observed by western blotting or immunohistochemistry. Conclusion: Up-regulation of moesin expression in glioblastoma cells resulted in more aggressive orthotopic glioblastoma growth in nude mice. This effect may be mediated by the regulation of several proliferation-, adhesion-, and invasion-related cancer genes, which may serve as future therapeutic targets for this recalcitrant disease.

Glioblastoma is the most common, aggressive, and recalcitrant form of brain cancer (1-3). Progression of glioblastoma may be mediated by many complex pathways and various regulatory molecules $(4,5)$. However, mechanisms of glioblastoma aggressiveness are poorly understood $(6,7)$.

Moesin, a member of the ezrin-radixin-moesin (ERM) protein family links the actin cytoskeleton and the plasma membrane, thereby playing a key role in cell morphology, motility, adhesion and other processes of tumorigenesis (810). Moesin expression has been correlated with pathologic grade and poor clinical outcome, including survival in astrocytoma $(11,12)$.

In our previous study, we demonstrated the role of moesin and showed that up-regulation of moesin expression in glioblastoma cells correlated with an increase in cell proliferation, invasion, and migration in vitro (13). In the present report we demonstrate the effect of moesin upregulation on the progression of glioblastoma in vivo.

\section{Materials and Methods}

Cell culture and transfection. The glioblastoma cell line U87 was purchased from the Shanghai Cell Bank of the Chinese Academy of Sciences. U87-GFP cells were obtained from AntiCancer Inc. (San Diego, CA, USA). All cells were cultured in RPMI 1640 medium (Thermo Fisher Scientific, CA, USA) containing 10\% fetal bovine serum (Thermo Fisher Scientific), $100 \mathrm{U} / \mathrm{ml}$ penicillin and $100 \mu \mathrm{g} / \mathrm{ml}$ streptomycin (Thermo Fisher Scientific) at $37^{\circ} \mathrm{C}$ with $5 \% \mathrm{CO}_{2}$. 
Cultured glioblastoma U87 cells were transfected with the H4645plenti-enhanced green fluorescent protein (EGFP)-moesin as described in our previous report (13). The H149 plenti-EGFP empty vector was used as negative control (U87-H149).

Animal care. BALB/c male nude mice (14), 4-6 weeks, 20-25 g, were purchased from the Nanjing Biomedical Research Institute of Nanjing University (Nanjing, P.R. China). All mice were maintained in a HEPA-filtered environment at $24-25^{\circ} \mathrm{C}$ and humidity was maintained at $50-60 \%$. All animals were fed with autoclaved laboratory rodent diet. Animal experiments were approved by the Animal Committee of Nanjing Origin Biosciences, P.R. China (OB1704).

Orthotopic mouse model of human glioblastoma. An orthotopic mouse model of human glioblastoma was used to assess tumor growth in vivo. The surgical orthotopic implantation (SOI) method followed published procedures (14). U87-GFP, U87-H149, and U87-H4645 cells $\left(5 \times 10^{6}\right)$ were first subcutaneously injected in the flank of nude mice. The tumors were harvested at the exponential growth phase and resected under aseptic conditions. Strong GFP expression of the tumor tissue was confirmed by fluorescence microscopy. Necrotic tissues were removed and viable tissues were cut with scissors and minced into 1$\mathrm{mm}^{3}$ fragments. Animals were anesthetized by injection of $0.02 \mathrm{ml}$ $50 \%$ ketamine, $38 \%$ xylazine, and $12 \%$ acepromazine maleate. After proper exposure of the left parietal bone following approximately a 1 $\mathrm{cm}$ long incision along the midline of the nude-mouse scalp, a U-shape cut was made on the left parietal bone with a sterile scalpel and blade. The U-shape bone was slightly lifted with a forceps and one $1 \mathrm{~mm}^{3}$ tumor fragment was inserted under the parietal bone. The bone incision was closed with forceps. The skin incision was closed with a 6-0 surgical suture. All procedures of the operation described above were performed under an 8x magnification microscope (Shanghai Precision Instruments, YZ20P5, Shanghai, P.R. China).

In vivo fluorescence imaging. Mice were monitored by real-time non-invasive GFP fluorescence imaging for glioma growth. Tumor volume was calculated using the formula $\left(\mathrm{L} \times \mathrm{W}^{2}\right) \times 1 / 2$, where $\mathrm{W}$ and $\mathrm{L}$ represent the perpendicular minor dimension and major dimension, respectively. A fluorescence stereo microscope (MZ650; Nanjing Optic Instrument Inc. P.R. China) equipped with D510 long-pass and HQ600/50 band-pass emission filters (Chroma Technology, Brattleboro, VT, USA) and a cooled color chargecoupled device camera (Qimaging, BC, Canada) was used. Selective excitation of GFP was produced through an illuminator equipped with HQ470/40 and HQ540/40 excitation band-pass filters (Chroma Technology). Images were processed and analyzed with the use of IMAGE PRO PLUS 6.0 software (Media Cybernetics, Silver Spring, MD, USA). At the end of the study, all mice were sacrificed and the tumors were removed, weighed and collected for further analysis.

Isolation of RNA and Reverse transcription-polymer chain reaction $(R T-P C R)$. Total RNA was isolated from tumor tissue with the Trizol reagent (Invitrogen, Carlsbad, California, USA) and reversely transcribed using a PrimeScript RT-PCR kit (Takara, Shimogyo-ku, Kyoto, Japan) according to the manufacturer's instructions, followed by PCR amplification with specific primers. The following primers were used to amplify most of the coding region of moesin (sense, 5 , CAGCATCAAGAACAAGAAAGGC 3', and antisense, 5' GGGGAG CATAGAAGACGAAG 3'), $\beta$-catenin (sense, 5' GCCACAAGATT
ACAAGAAACGG 3', and antisense, 5' ATCCACCAGAGTGAAA AGAACG 3'), MMP-2 (sense, 5' CATCGTAGTTGGCTGTGGTCG 3', and antisense, 5'GTCTTCCCCTTCACTTTCCTG3'), ICAM1 (sense, 5'TGATGATGACAATCTCATACCG3', and antisense, 5'AAATTCCCAGCAGACTCCAAT3'), CD44 (sense, 5'TCTGTC TGTGCTGTCGGTGAT3', and antisense, 5'GCAACCCTACTGA TGATGACG3') and Glyceraldehyde 3-phosphate dehydrogenase $(G A P D H)$ (sense, 5'-GCACCGTCAAGGCTGAGAAC-3' and antisense, 5'-TGGTGAAGACGCCAGTGGA-3').

Quantitative real-time PCR was performed using a 7300 Realtime PCR system (Applied Biosystems, Waltham, MA, USA). PCR was carried out in a volume of $20 \mu \mathrm{l}$ containing $10 \mu \mathrm{l} 2 \times \mathrm{qPCR}$ Master Mix, $2 \mu \mathrm{l}$ of cDNA, $0.2 \mu \mathrm{l}$ each primer and $0.4 \mu \mathrm{l}$ ROX Reference Dye 1 . Reaction conditions for amplification of target genes were one cycle of denaturation at $95^{\circ} \mathrm{C}$ for $5 \mathrm{~min}$, followed by 40 cycles of $5 \mathrm{sec}$ at $95^{\circ} \mathrm{C}, 30 \mathrm{sec}$ annealing at $60^{\circ} \mathrm{C}$, and $40 \mathrm{sec}$ prolongation at $72^{\circ} \mathrm{C}$. Data were analyzed by the relative standardcurve method and normalized to $G A P D H$ expression. Relative RNA expression in the glioblastoma cell lines was calculated using the $2^{-\Delta \Delta C t}$ method. All samples were performed in triplicate.

Western blotting. Protein from tumor tissue was extracted with RIPA buffer (Roche Diagnostics, IN, USA). Protein concentrations were determined by the Bradford assay (Bio-Rad, Hercules, CA, USA). Total proteins were separated by sodium dodecylsulfatepolyacrylamide gel electrophoresis and electrophoretically transferred to a polyvinylidene fluoride membrane (Millipore, Bedford, MA, USA). The membranes were blocked with $5 \%$ nonfat milk at room temperature for $1 \mathrm{~h}$ and then incubated for $2 \mathrm{~h}$ with primary antibodies to moesin, $\beta$-catenin, ICAM- 1 , or $\beta$-actin (Cell Signaling Technology, Boston, MA, USA). The membranes were then incubated for $1 \mathrm{~h}$ with an appropriate horseradish peroxidaselinked secondary antibody (Santa Cruz Biotechnology, Dallas, TX, USA). Electrochemiluminescence was performed according to the manufacturer's instructions using a ChemiDoc ${ }^{\mathrm{TM}}$ Touch Imaging System (Bio-Rad). Quantity One software (Bio-Rad) was used to quantify the density of bands.

Immunohistochemistry. Tumor tissues were fixed in $10 \%$ buffered formalin and paraffin-embedded. For immunohistochemistry, sections were incubated with primary antibodies against MMP-2 and CD44 (all from BD Biosciences, San Diego, CA, USA) overnight at $4{ }^{\circ} \mathrm{C}$ after permeabilization with a solution of $0.1 \%$ sodium citrate and $0.1 \%$ Triton X-100 and blocking with $10 \%$ rabbit serum. After washing with $\mathrm{pH} 7.4$ phosphate-buffered saline (PBS), the sections were incubated with secondary antibody (Dako REAL EnVision Detection System, Dako, Cambridgeshire, UK) for $30 \mathrm{~min}$ at room temperature. Color development was performed with 3, 3'-diaminobenzidine (DAB). Nuclei were lightly counterstained with hematoxylin. The slides were viewed at $\times 400$ magnification, and positive cells were recognized by the appearance of brown staining. The expression level was quantified by the average optical density (AOD) of the positive cells in five fields per sample with ImagePro Plus 6.0 software (Media Cybernetics, Silver Spring, MD, USA).

Statistical analysis. Statistical analysis was performed using SPSS16.0 software (SPSS Inc., Chicago, IL, USA). All results are expressed as mean \pm SD. Comparisons between two groups were made with the Student's $t$-test. $p<0.05$ was considered significant. 
A

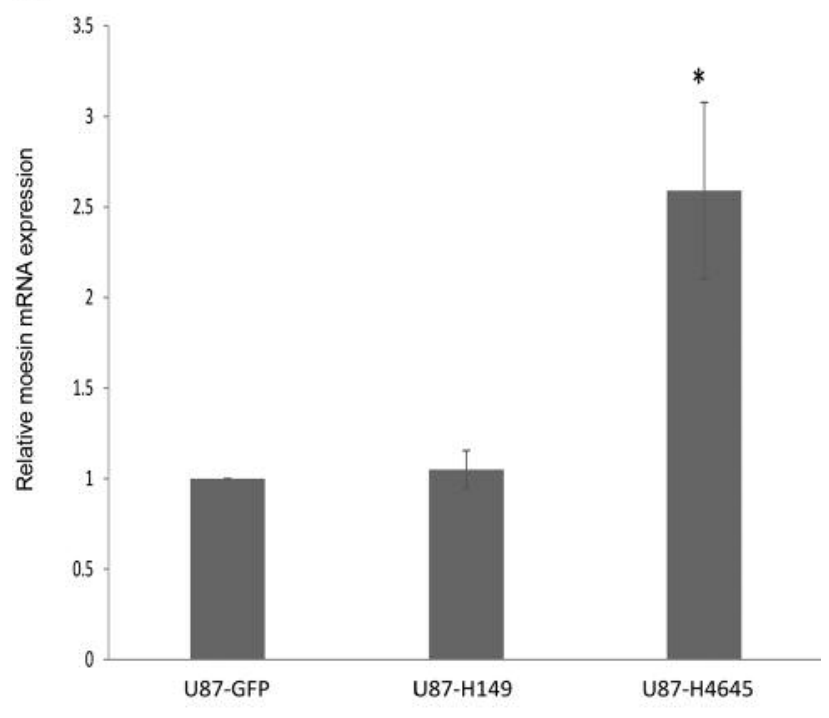

B

U87-GFP U87-H4645 U87-H149
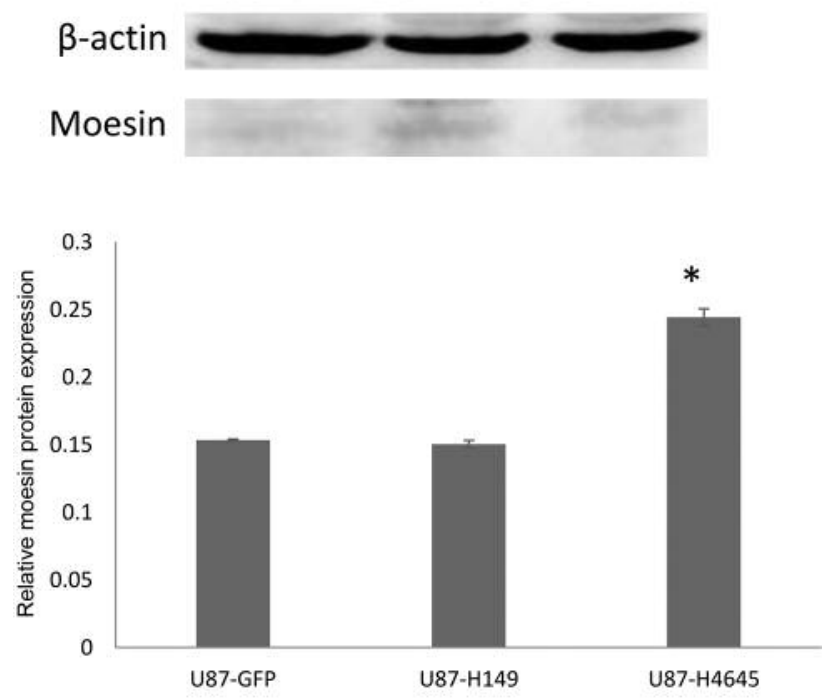

Figure 1. Moesin up-regulation in glioblastoma. Moesin expression in orthotopic glioblastoma tumors was analyzed with RT-PCR and western blotting. A: Moesin mRNA expression in U87-GFP-, U87-H149-, and U87-H4645-derived glioblastoma. B: Moesin protein expression in U87GFP, U87-H149 and U87-H4645 derived glioblastoma. * $p<0.01$, when compared with untransfected and vector-control group.

\section{Results and Discussion}

Moesin up-regulation increases orthotopic glioblastoma growth. Moesin up-regulation was achieved by transfecting the U87 glioblastoma cell lines with the H4645-plentiEGFP-moesin expression vector as described in our previous study (13). In the present study, the transfected cells were implanted to establish an orthotopic mouse tumor model of glioblastoma. The expression level of moesin mRNA and protein was significantly increased in the tumors derived from transfected U87-H4645 cells compared to tumors derived from untransfected cells (U87-GFP) and vector control (U87-H149) $(p<0.01)$ (Figure 1).

Moesin up-regulation increases orthotopic glioblastoma growth. Effect of moesin up-regulation on glioma growth was determined in an orthotopic mouse model. Real-time non-invasive fluorescence imaging was used to longitudinally quantitate glioma growth. Representative fluorescence images, tumor growth curves, and final tumor weight in each group are shown in Figure 2A, B and C, respectively. The glioma growth rate was significantly increased in mice implanted with transfected U87-H4645 cells compared to untransfected and vector control tumors $(p<0.01)$. The final weight of the transfected U87-H4645 tumor was also significantly increased compared to untransfected and vector control tumors $(p<0.01)$.

Effect of moesin up-regulation on the expression of related genes. The effect of moesin up-regulation on the expression of genes associated with some cancers, including $\beta$-catenin, CD44, MMP-2, ICAM-1, and PCNA was examined (Figure 3A). These genes in the glioblastoma derived from the transfected U87-H4645 cells were significantly increased compared with the untransfected and vector control $(p<0.01)$. Furthermore, a similar change in protein expression of these molecules was observed by western blotting or immunohistology. $\beta$-catenin and ICAM-1 protein was significantly increased in the glioblastoma derived from transfected U87-H4645 cells compared with the untransfected and vector control $(p<0.01)$ (Figure 3B). Immunohistochemical analysis showed that the glioblastoma derived from transfected U87-H4645 cells had enhanced expression of CD44, MMP-2, and PCNA compared with the untransfected and vector control $(p<0.05)$ (Figure 3C).

In our previous study, we found that $\beta$-catenin expression was affected by moesin expression in glioblastoma cells in vitro (13). In the present study, more genes were investigated, which are likely related to glioma growth, adhesion, and invasion. CD44 is a hyaluronan transmembrane receptor and stem-cell marker involved in cell-cell and cell-matrix interactions. Its expression has been associated with glioblastoma cell migration, invasion, and treatment resistance (15-17). CD44 was identified as a transducer of signals upstream of the $\mathrm{Wnt} / \beta$-catenin pathway in glioblastoma cells (18). Matrix metalloproteinase MMP-2 belongs to the matrix metalloproteinases family and may be involved in cell proliferation, motility, invasion, and angiogenesis $(18,19)$. Intercellular adhesion molecule-1 (ICAM-1) was expressed in several glioma stem cell lines, and overexpression of ICAM-1 


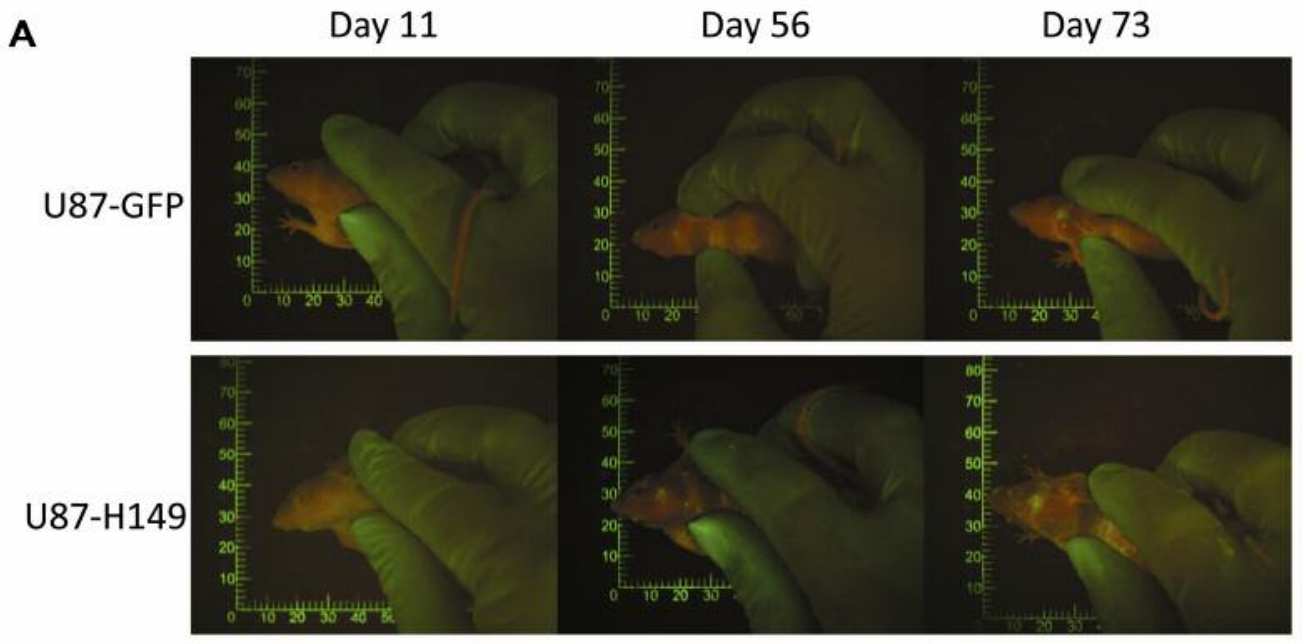

Day 73 (Open imaging)
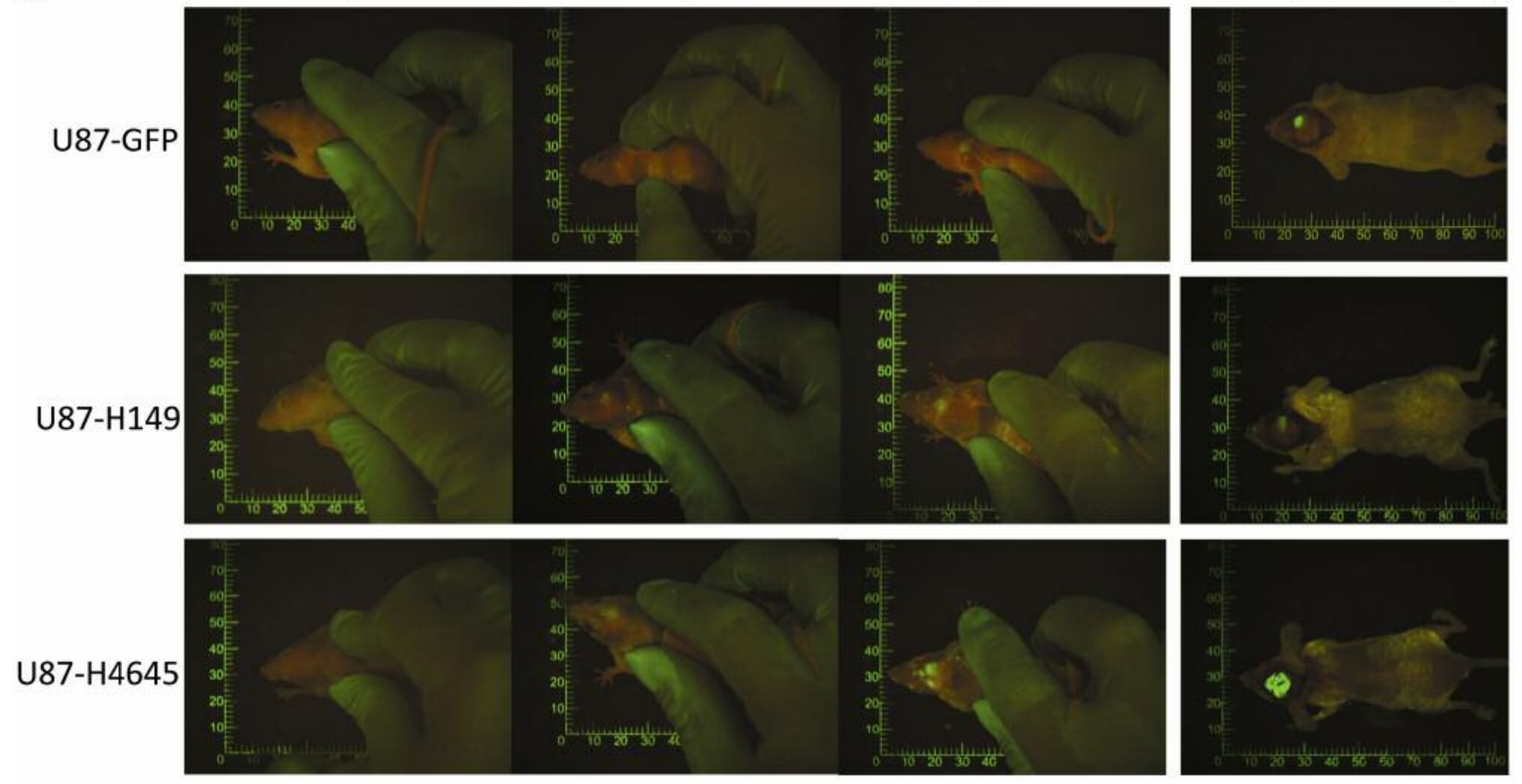

B
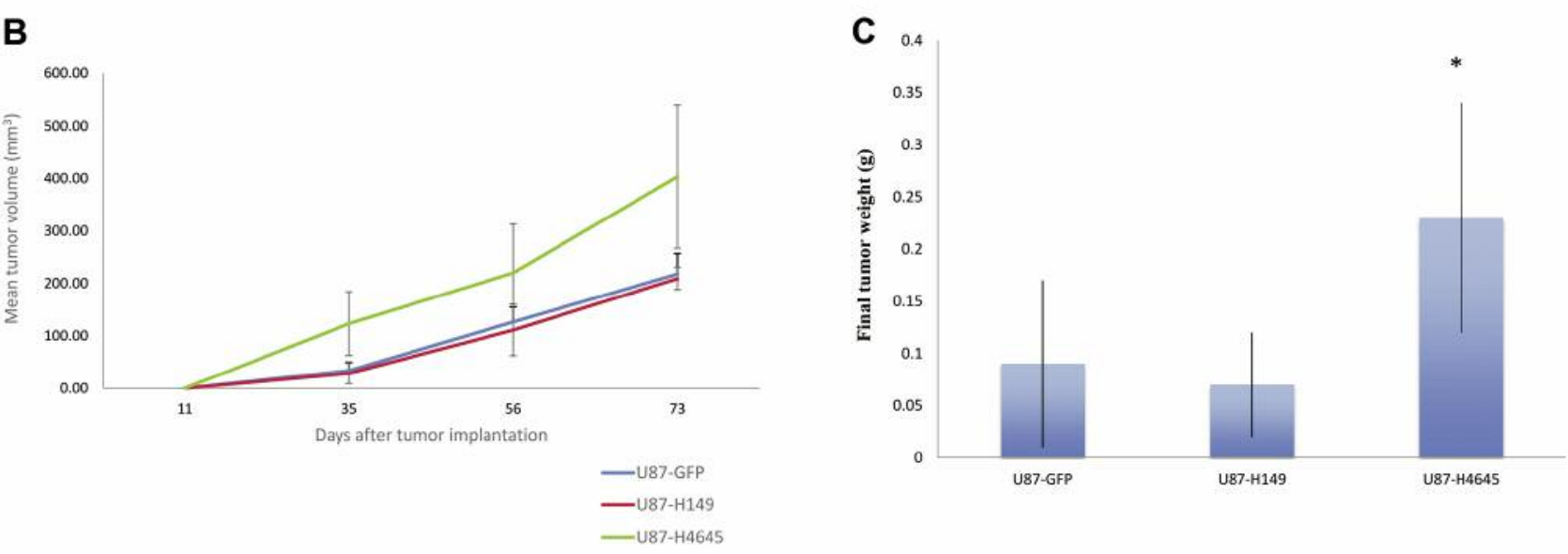

Figure 2. Moesin up-regulation increases orthotopic glioblastoma growth. Real-time non-invasive fluorescence imaging was used to visualize and track tumor growth. A: Sequential in vivo longitudinal non-invasive fluorescence imaging of glioblastoma on day 11, 56 and 73 after orthotopic implantation of U87-GFP, U87-H4645, and U87-H149 cells. B: Glioblastoma growth curves for U87-GFP, U87-H4645 and U87-H149. C: Final tumor weights of U87-GFP, U87-H4645 and U87-H149 glioblastoma. ${ }^{*} p<0.01$, when compared with untransfected and vector-control group.

has been associated with tumor growth, progression, and angiogenesis in many cancers (20). Expression of proliferating cell nuclear antigen (PCNA) occurs only in proliferating cells and is associated with metastasis and tumor grade (21). Previous studies on PCNA protein expression levels in astrocytoma and oligoastrocytoma indicated that its increased expression correlated with higher tumor grade (22) and decreased patient survival $(23,24)$.
WNT/ $\beta$-catenin signaling pathway and downstream modulators were associated with histological malignancy grade and with a worse prognosis for patients with glioma (25). The present results indicate that moesin induces $\mathrm{Wnt} / \beta$-catenin pathway activation and up-regulates proliferation-, adhesion-, and invasion-related genes in glioblastoma, which may serve as future targets for this recalcitrant disease. 

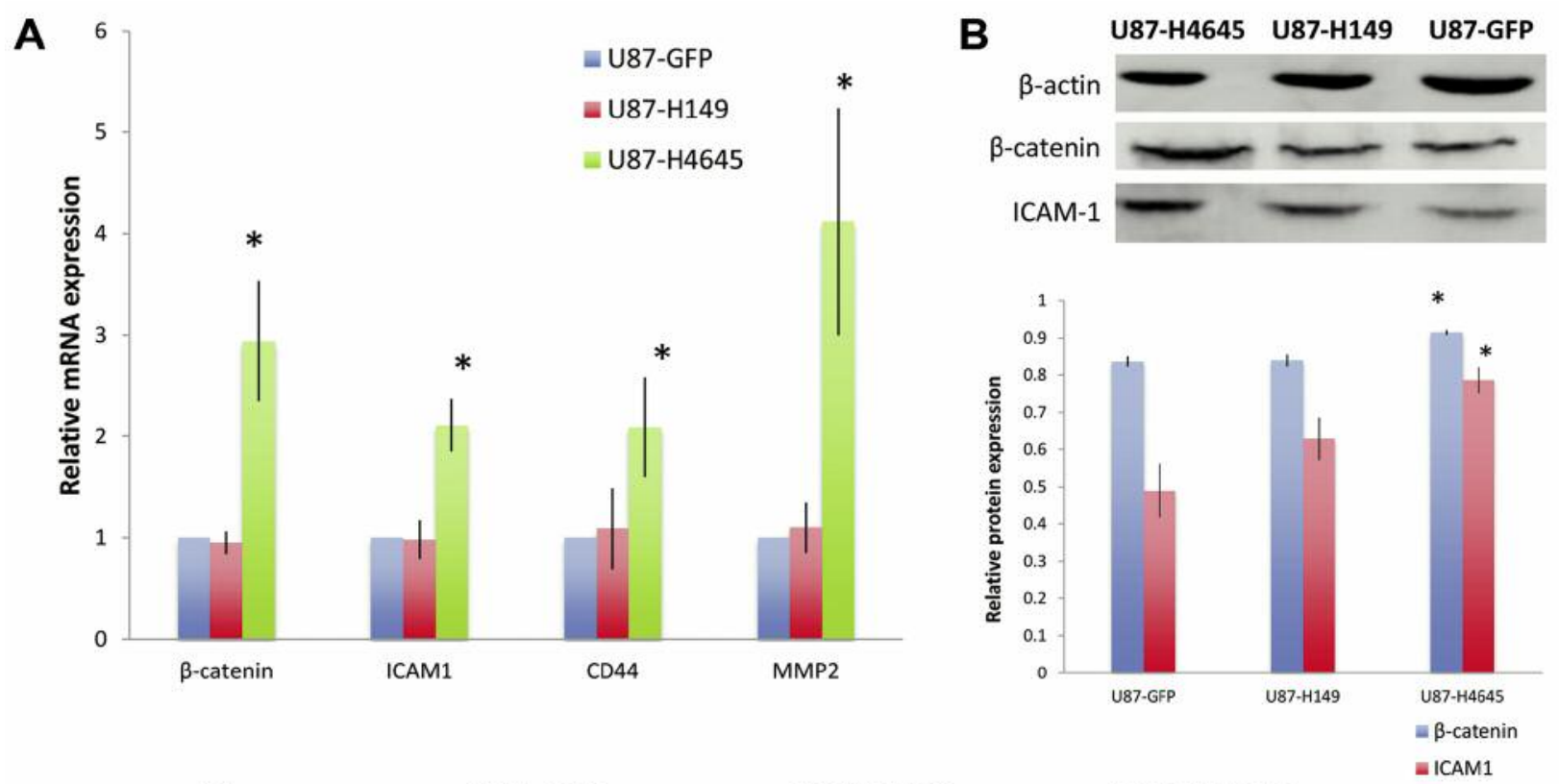

\section{C}

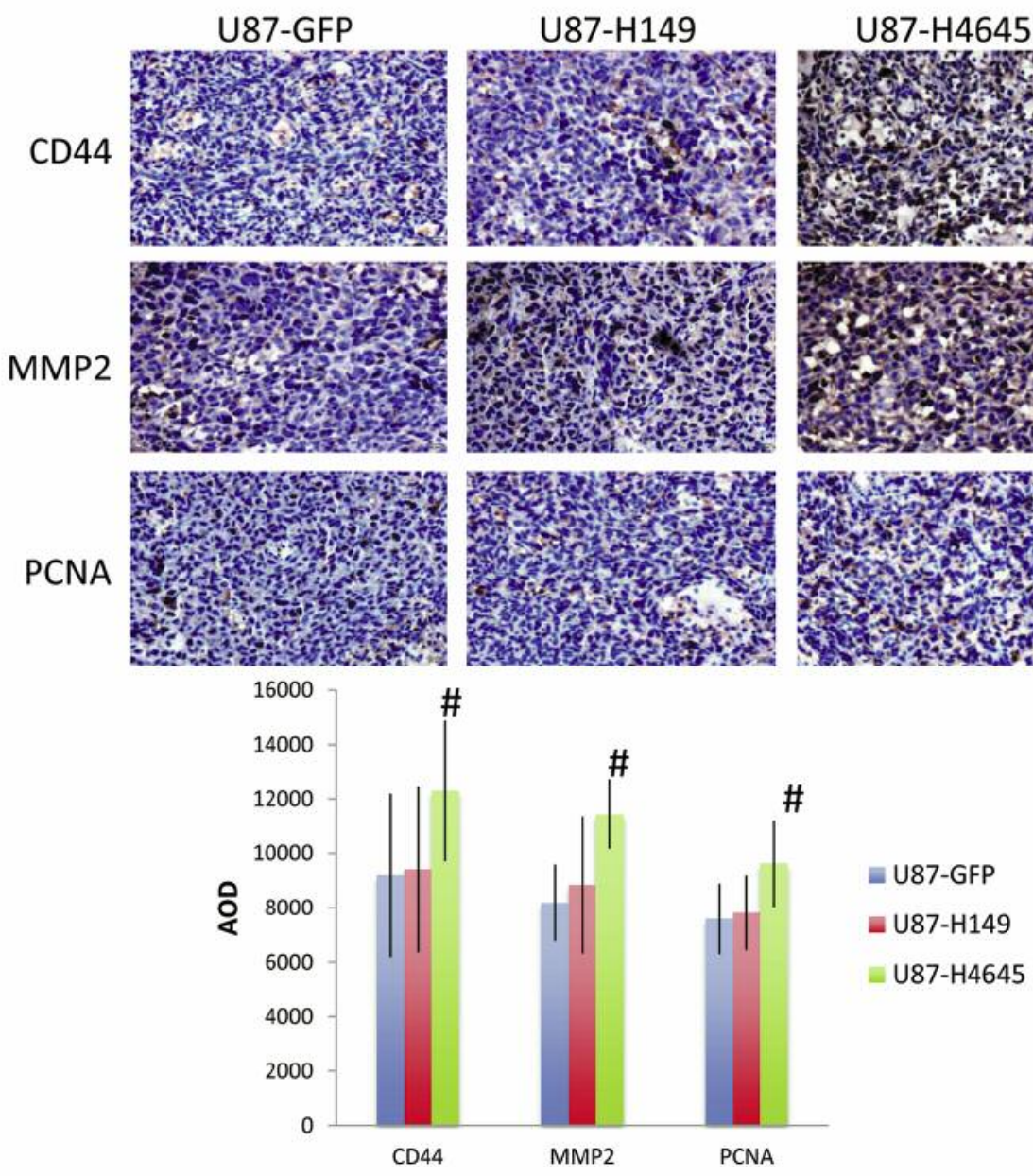

Figure 3. Effect of moesin up-regulation on the expression of related genes. Expression of $\beta$-catenin, CD44, MMP-2, ICAM-1 and PCNA genes in U87-GFP, U87-H149 and U87-H4645-derived glioblastoma analyzed with RT-PCR, western blotting, or immunohistochemistry. A: RT-PCR for $\beta$-catenin, CD44, MMP-2, and ICAM-1 mRNA expression. B: Western blotting for $\beta$-catenin and ICAM-1 protein expression. C: Immunohistochemical staining of CD44, MMP-2 and PCNA for protein expression. ${ }^{*} p<0.01$, ${ }^{*} p<0.05$ when compared with untransfected and vector-control groups. 


\section{Acknowledgements}

This work was mainly supported by the fund for "the fifth 333 highlevel talent training project" of Jiangsu Province; the fund for "six high-level healthy talent" projects of Jiangsu Province (No. LGY2017016).

\section{Conflicts of Interest}

The Authors have no conflicts of interest in regard to this study.

\section{References}

1 Bonavia R, Inda MM, Cavenee WK and Furnari FB: Heterogeneity maintenance in glioblastoma: a social network. Cancer Res 71: 4055-4060, 2011.

2 Mao H, Lebrun DG, Yang J, Zhu VF and Li M: Deregulated signaling pathways in glioblastoma multiforme: molecular mechanisms and therapeutic targets. Cancer Invest 30: 48-56, 2012.

3 Stupp R, Hegi ME, van den Bent MJ, Mason WP, Weller M, Mirimanoff RO and Cairncross JG; European Organisation for Research and Treatment of Cancer Brain Tumor and Radiotherapy Groups; National Cancer Institute of Canada Clinical Trials Group: Changing paradigms-an update on the multidisciplinary management of malignant glioma. Oncologist 11: 165-180, 2006.

4 Pham MH, Zada G, Mosich GM, Chen TC, Giannotta SL, Wang $\mathrm{K}$ and Mack WJ: Molecular genetics of meningiomas: a systematic review of the current literature and potential basis for future treatment paradigms. Neurosurg Focus 30: E7, 2011.

5 Nakada M, Nakada S, Demuth T, Tran NL, Hoelzinger DB and Berens ME: Molecular targets of glioma invasion. Cell Mol Life Sci 64: 458-478, 2007.

6 Canadian Cancer Society's Steering Committee: Canadian Cancer Statistics 2010. Toronto: Canadian Cancer Society; 2012. http://www.cancer.ca/statistics.

7 Dvorak HF, Weaver VM, Tlsty TD and Bergers G: Tumor microenvironment and progression. J Surg Oncol 103: 468-474, 2011.

8 Tsukita S and Yonemura S: ERM proteins: head-to-tail regulation of actin-plasma membrane interaction. Trends Biochem Sci 22: 53-58, 1997.

9 Speck O, Hughes SC, Noren NK, Kulikauskas RM and Fehon RG: Moesin functions antagonistically to the Rho pathway to maintain epithelial integrity. Nature 421: 83-87, 2003.

10 Bretscher A: Regulation of cortical structure by the ezrinradixinmoesin protein family. Curr Opin Cell Biol 11: 109-116, 1999.

11 Wu M, Liu D-Y, Yuan X-R, Liu Q, Jiang XJ, Yuan D, Huang J, $\mathrm{Li} \mathrm{XJ}$ and Yang ZQ: The expression of moesin in astrocytoma: correlation with pathologic grade and poor clinical outcome. Med Oncol 30: 372, 2013.

12 Tynninen O, Carpen O, Jaaskelainen J, Paavonen T and Paetau A: Ezrin expression in tissue microarray of primary and recurrent gliomas. Neuropathol Appl Neurobiol 30: 472-477, 2004.
13 Wang Q, Lu X, Zhao S, Pang M, Wu X, Wu H, Hoffman RM, Yang $\mathrm{Z}$ and Zhang $\mathrm{Y}$ : Moesin expression is associated with glioblastoma cell proliferation and invasion. Anticancer Res 37: 2211-2218, 2017.

14 Momiyama M, Zhao M, Kimura H, Tran B, Chishima T, Bouvet M, Endo I and Hoffman RM: Inhibition and eradication of human glioma with tumor-targeting Salmonella typhimurium in an orthotopic nude-mouse model. Cell Cycle 11: 628-632, 2012.

15 Tews DS and Nissen A: Expression of adhesion factors and degrading proteins in primary and secondary glioblastomas and their precursor tumors. Invasion Metastasis 18: 271-284, 1998.

16 Okamoto I, Kawano Y, Murakami D, Sasayama T, Araki N, Miki $\mathrm{T}$, Wong AJ and Saya H: Proteolytic release of CD44 intracellular domain and its role in the CD44 signaling pathway. J Cell Biol 155: 755-762, 2001.

17 Okamoto I, Kawano Y, Tsuiki H, Sasaki J, Nakao M, Matsumoto M, Suga M, Ando M, Nakajima M and Saya H: CD44 cleavage induced by a membrane-associated metalloprotease plays a critical role in tumor cell migration. Oncogene 18: 1435-1446, 1999.

18 Rao JS, Steck PA, Mohanam S, Gokaslan ZL and Rao JS: Elevated levels of M[r] 92,000 type IV collagenase in human brain tumors. Cancer Res 53: 2208-2211, 1993.

19 Egeblad $\mathrm{M}$ and Werb Z: New functions for the matrix metalloproteinases in cancer progression. Nat Rev Cancer 2: 161-174, 2002.

20 Usami Y, Ishida K, Sato S, Kishino M, Kiryu M, Ogawa Y, Okura M, Fukuda $\mathrm{Y}$ and Toyosawa S: Intercellular adhesion molecule-1 (ICAM-1) expression correlates with oral cancer progression and induces macrophage/cancer cell adhesion. Int $\mathrm{J}$ Cancer 133: 568-578, 2013.

21 Kartalou M and Essigmann JM: Mechanisms of resistance to cisplatin. Mutat Res 478: 23-43, 2001.

22 Kubben FJ, Peeters-Haesevoets A, Engels LG, Baeten CG, Schutte B, Arends JW, Stockbrügger RW and Blijham GH: Proliferating cell nuclear antigen (PCNA): a new marker to study human colonic cell proliferation. Gut 35: 530-535, 1994.

23 Swift LH and Golsteyn RM: Genotoxic anti-cancer agents and their relationship to DNA damage, mitosis, and checkpoint adaptation in proliferating cancer cells. Int J Mol Sci 15: 34033431, 2014.

24 Cunningham JM, Kimmel DW, Scheithauer BW, O'Fallon JR, Novotny PJ and Jenkins RB: Analysis of proliferation markers and p53 expression in gliomas of astrocytic origin: relationships and prognostic value. J Neurosurgery 86: 121-130, 1997.

25 Denysenko T, Annovazzi L, Cassoni P, Melcarne A, Mellai M and Schiffer D: WNT/ $\beta$-catenin signaling pathway and downstream modulators in low- and high-grade glioma. Cancer Genomics Proteomics 13: 31-45, 2016. 